\title{
Kişilik ve Yaratıcılık İliş̧kisini İnceleyen Çalışmaların Kullanılan Ölçme Araçlarına Göre Değerlendirilmesi
}

\author{
Prof. Dr. Hamit COŞKUN* \\ Abant İzzet Baysal Üniversitesi, Fen Edebiyat Fakültesi, Psikoloji Bölümü, Bolu / Türkiye
}

\section{Uzm. Psk. Ahmet Yasin ŞENYURT}

Abant İzzet Baysal Üniversitesi, Fen Edebiyat Fakültesi, Psikoloji Bölümü, Bolu / Türkiye

\section{$\ddot{\mathbf{O} z}$}

Yaratıcılık kavramına ilişkin önemli sorunlardan biri yaratıcılığı etkileyen kişisel farklılıkların ortaya çıkarılmasıdır. Özellikle yaratıcılık ile kişilik faktörleri arasındaki ilişkiyi anlamaya yönelik birçok araştırma olsa da bu çalışmaların sonuçları tutarsızlık gösterebilmektedir. Bu derlemenin varsayımı yaratıcılık ve kişilik arasındaki ilişkinin yönü ve gücündeki değişkenliğin yaratıcılık ölçümünde kullanılan araçların farklılaşmasından kaynaklandığıdır. Bu çalışmada, alanyazında yaratıcılık ve kişilik arasındaki ilişkiyi inceleyen çalışmalar, yaratıcılı̆̆ı değerlendirmek için kullanılan farklı ölçüm araçları temelinde gruplandırılarak ele alınmıştır. Genel olarak, yaratıcılık ile kişilik ilişkisini inceleyen çalışmaların sonuçları, yaratıcılığın alt boyutlarına bağlı olarak dışadönüklük, deneyime açıklık ya da nevrotiklik ile yaratıcılık arasında ilişki

* Sorumlu Yazar. Tel: +905355645889Ｅ-posta: hamitcoskun2000@ gmail.com

(C) 2015 Kalem Eğitim ve Sağlık Hizmetleri Vakfi. Bütün Hakları Saklıdır. ISSN: 2146-5606 
olduğunu göstermektedir. Fakat bu çalışmalarda kullanılan farklı yaratıcılık ölçümleri arasında gözlemlenen düşük korelasyon ve ölçüm aracına bağlı olarak değişen nevrotiklik-yaratıcılık ilişkisi varsayımımızı desteklemektedir. Çalışma sonucunda kişilik-yaratıcılık ilişkisinin iki adım modeli çerçevesinde ele alınmasının gelecek çalışmalar açısından daha geçerli sonuçlar doğuracağı değerlendirilmiş̧ir.

Anahtar Kelimeler: Yaratıcılık; Kişilik; Iraksak düşünme; Beş faktör modeli; Yaratıcılık testleri.

\title{
A Review of Studies Investigating Personality and Creativity Relationship in Light of Creativity Measurement Methods
}

\begin{abstract}
One of the key issues relating to the concept of creativity is the discovery of personal differences affecting creativity. In particular, although a lot of research are conducted to understand the relationship between creativity and personality factors, the results of these studies can be inconsistent. The assumption of this review is that the variation in direction and strength of the relationship between creativity and personality is due to the differing methods used to measure creativity. In this study, studies examining the relationship between creativity and personality in the literature, were discussed on the basis of their various methods. In general, results of the studies examining the relationship between creativity and personality indicate that extraversion, openness to experience, and neuroticism are related to creativity, depending on the dimensions of creativity. However, low correlation between different measures of creativity and variation of neuroticism-creativity relationship due to measurement, supports our assumption. At the end, it is suggested that personality and creativity relation should be investigated in lights of the two step model since such approach will lead to more valid results for future studies.
\end{abstract}

Keywords: Creativity; Personality; Divergent thinking; Five factor model; Creativity tests. 


\section{Extended Summary}

\section{Purpose}

It has been suggested that extraversion and openness to experience, as personality traits, are positively correlated with creativity. However, there are conflicting results for the relationship of creativity with neuroticism, conscientiousness traits. Differences in the concept of creativity and different measurements of creativity are the core factors of these contradictory results. The most accepted definition of creativity is that "Creativity is the process of revealing a genuine product". Product would be an artistic painting for one researcher, but a research proposal for another. Process has also different meanings among researchers; divergent thinking and convergent thinking. Some researches, the ones using Remote Associates Test, focus on convergent thinking, whereas others focus on divergent thinking tasks such as Consequences Tests or Guilford Alternative Uses Test. The aim of this study was to evaluate personality and creativity relationship literature by grouping the results in terms of the method that was used to measure creativity. Literature will also be discussed in the light of the recent models including step model and dual pathway model.

\section{Discussion}

Torrance Tests of Creative Thinking (TTCT) is one of the most widely used measure of creativity. King, Walker ve Broyles (1996) found that TTCT verbal subscale was positively correlated with extraversion and openness to experience. Another meaure is Guilford Alternate Uses Test. Extraversion was consistently found to be positi- 
vely correlated with creativity in this measure? However, there were contraversial results for openness to experience trait. Consequences test studies provide controversial results, except for openness to experience trait. Some studies found positive relationship between extraversion and creativity while others did not report any relationship. Studies, which used Remote Associate Test to measure creativity, found a positive effect of extraversion only.

Metaanalytic studies and reviews of scientific creativity have some contraversial results. According to Batey and Furnham (2006), scientific creativity is positively associated with openness to experience and conscientiousness whereas negatively associated with neuroticism and extraversion. On the otherhand, Feist (1998) suggested that creative scientists were more extravert, conscientiousness, and open to new experiences than non-creative scientists.

In terms of artistic creativity, conscientiousness was assumed to be negatively but openness was assumed to be positively related to creativity by Feist (1998). Batey and Furnham (2006) supported evidence for these assumptions. In addition, they suggested that neuroticism was also positively related and extraversion was negatively related to artistic creativity. Studies which compare creativity measure with each other usually found low correlations between them.

\section{Conclusion}

The most important limitation of this study is not covering studies which investigated personality creativity relationship beyond the five factor model. Not addressing all studies may be regarded as another 
important limitation. However, studies included in our review reflect inconsistencies in the literature.

When the results were evaluated, extraversion and openness to experience, stand out as important personality traits that enhance creativity. The relationship between conscientiousness, neuroticism, and creativity varies according to the type of creativity.

According to the two-step model of creativity, creativity consists of idea generation and steps. Nowadays commonly used divergent thinking tests and inventories measure the step of idea generation. The second part is idea selection which requires convergent thinking. It would be a realistic expectation that different personality traits would have different effect on these two steps.

Future studies should identify cognitive processes underlying domains of creativity. In addition, reliable and valid measures of these processes should be developed. Personality factors, intelligence, environmental stimuli and mood might have different effects on different mental processes. Research designs which aim to explain these differences will enable us to understand creativity in a more valid and reliable way.

\section{Giriş}

Yaratıcılık kavramı -tarihsel gelişimi- psikolojinin araştırma konusu olduğundan bu yana, araştırmacılar yaratıcılığı arttıran veya azaltan bireysel farklılıklara odaklanmışlardır. Zekâ, cinsiyet, yaş, psikopatolojiler ve kişilik özellikleri 1960'lardan günümüze yaratıc1- 
lıkla ilişkisi en çok araştırılan kavramlardır (Batey ve Furnham, 2006; Foley ve Park, 2005; Kyaga, Landén, Boman, Hultman, Långström, ve Lichtenstein, 2013). Günümüzde bu kavramların birçoğunun yaratıc1lıkla ilişkisi net bir biçimde tanımlanmıştır. Meselâ, zeka ile yaratıcılık arasındaki ilişki üzerine olan tartışmalar, belli bir eşik düzeye ( $\mathrm{IQ}=120)$ kadar pozitif korelasyon gösterdiği ve daha yüksek IQ seviyelerinde bu ilişkinin gözlemlenmediğini öne süren eşik düzey hipotezine odaklanmıştır (Jauk, Benedek, Dunst ve Neubauer, 2013). Bununla birlikte yaratıcılık ile kişilik arasındaki ilişki hâlen net bir şekilde ifade edilememektedir. Kişilik özelliklerinden dişadönüklük ve deneyime açıkl1ğın yaratıcılıkla pozitif bir yönde ilişkisi olduğu kabul görse de nevrotiklik, uyumluluk ve bilinçliliğin yaratıcılıkla ilişkisine yönelik birbiriyle çelişen sonuçlar yayınlanmaya devam etmektedir. Bu çelişkilerin temelinde yaratıcılık ve kişilik kavramlarının tanımına ve ölçümüne yönelik farklı görüşlerin yattığı değerlendirilebilir.

Yaratıcılık kavramının genel kabul gören tanımlarından biri, yaratıcılığın orijinal ve uygulanabilir fikir, ürün ya da hizmet üretmek veya var olan fikir, ürün ya da hizmetin alışılmadık şekilde kullanılması olduğudur (Csikszentmihalyi, 2013, s.28). Benzer bir şekilde, Paulus ve Nijstad'a (2003) göre ise yaratıcılık yararlı veya kullanışı, aynı zamanda orijinal fikirlerin geliştirilmesi sürecidir. Guilford (akt; Almeida, Prieto, Ferrando, Oliveira ve Ferrandiz, 2008) ve Mayer (1999) yaratıcılığın akıcılık, özgünlük ve esneklik özelliklerine vurgu yaparken, Torrance (1965, s.663) ise yaratıcılığı, problem çözme ve fikirleri paylaşmaya yönelik bir süreç olarak değerlendirmiştir. 
$\mathrm{Bu}$ tanımların en önemli ortak noktası, yaratıcılığın orijinal bir ürün ortaya çıkarma süreci olduğudur. Burada düşünce, hizmet, sanat eseri veya problem çözme yöntemi bir ürün olarak adlandırılabilir. Ürün tanımındaki karmaşanın önemli bir kısmı, yaratıcılığı ölçen araçların da en az tanımlar kadar çok olması ve daha önemlisi bu test ve ölçeklerin farklı zihinsel süreçleri ölçmesinden kaynaklanmaktadır.

Başka bir deyişle yaratıcılık farklı zihinsel süreçleri, farklı davranışsal belirtilerle ölçen ölçüm araçları ile değerlendirilmektedir. $\mathrm{Bu}$ araçlardan en sık kullanılanı Torrance Yaratıcılık Testi (TYT) (Torrance, 1966, akt; Kim, 2006)'dir. Test kapsamında bireylerin rraksak düşünme becerisi ölçülmekte ve bu beceri doğrultusunda yaratıcılık puanları hesaplanmaktadır. Bir başka sık kullanılan test ise bir objenin veya eşyanın (örneğin tuğlanın) değişik kullanımlarına dayalı Guilford Alternatif Kullanım Testi (GAKT) (Guilford, 1967, akt; Walker ve Jackson, 2014)'dir. Bu iki testle birlikte yaratıcılığı problem çözme performansıyla ölçen ve beyin yazımı tekniğini kullanarak gruplarda (veya bireysel) orijinal düşünce üretimiyle yaratıcılık performansını değerlendiren araçlar da sıklıkla kullanılmaktadır (Paulus, 2000; Gültepe, 2014). Bunlar dışında, sanatsal yaratıcılığı performansa dayalı olarak ölçen ve sanatçıların üretimlerinin hakemler vasıtasıyla değerlendirildiği ölçümler de kullanılmaktadır (Yi, Plucker ve Guo, 2015). Ya da akademik yaratıcılığı ölçen performans değerlendirmeleri veya hipotez oluşturma/test etme gibi akademik yetenekleri ölçen uygulamalar veya özbildirim ölçeklerinin kullanımı literatürde yer almaktadır (Ayas ve Sak, 2014; Frederiksen ve Ward, 1978; Hu ve Adey, 2002). Özetle yaratıcılık ölçümü dediğimiz olgu tek bir kavramı, tek bir zi- 
hinsel beceriyle ölçmemekte bunun yerine günlük (genellikle problem çözme veya düşünce üretme performansına dayalı), akademik veya sanatsal yaratıcılık gibi farklı kavramları, birbirinden farklı ölçüm aracıyla değerlendirmektedir.

Hoover (1979) 35 yıl önce yaratıcılığın farklı boyutlarının olmasının sonuçlarını ve boyutların ölçümünde kullanılan araçların düşük geçerliğine ve güvenirliğine yönelik sorunları dile getirmiştir. Bu eleştiriler:

“1. Yaratıcıllk ölçümünde hakem, uzman ya da öğretmen değerlendirmelerinde düşük hakemler arası güvenirlik, halo etkisi ve düşük ayırt edici geçerliğin olması,

2. Yaratıcılı̆̆ın akıcılık, esneklik ve uygulanabilirlik boyutların ayırt etmede yetersizlikler,

3. Testler ve envanterlerin ise en iyi ihtimalle gerçek hayattaki yaratıcılı̆̆ın bir çeşit karşıllı̆̆ olması (Hoover, 1979, s. 1)."dir.

Hoover'ın (1979) eleştirilerinin günümüzde de geçerliğini koruduğunu görmekteyiz. Meselâ, yakın dönemdeki birçok yayın özellikle "Iraksak Düşünme” testlerinin yaratıcılığın birebir karşılı̆̆ı olarak kullanılmasındaki yanlışlıklara vurgu yapmaktadır (Kim, 2006; Cropley, 2006). Ayrıca ölçüm yöntemlerinin çeşitlenmesi nedeniyle sadece hakemler arası düşük güvenirlik değil; aynı boyutu ölçtüğü varsayılan test ve ölçekler arasında da düşük korelasyonlar gözlenmektedir.

Yaratıcılık ölçümündeki sorunların devam etmesine karşın, kişi- 
lik ölçümüne ilişkin sorunlar ilk dönem çalışmalarına kıyasla çok daha az yaşanmaktadır. Bu durumun en önemli nedeni kişilikle ilgili Büyük Beşli Modelinin (BBM) genel anlamıyla kabul görmesidir. Yaratıcılık, kişilik ilişkisini inceleyen ilk dönem çalışmalarda görülen, iki veya üç faktörlü kişilik yaklaşımı günümüzde neredeyse hiç kullanılmamaktadır. Her ne kadar, kişilik ölçümünde NEO-FFI (McCrea ve Costa, 2004), International Personality Item Pool (Goldberg ve diğer., 2006) veya Türkiye'de geliştirilen Temel Kişilik Özellikleri Ölçeği (Gençöz ve Öncül, 2012) gibi farklı ölçüm araçları kullanılsa da bütün bu ölçekler 5 faktörlü bir yapıyı temel almaktadır. Temel Kişilik Özellikleri Ölçeği, 6 faktörlü yapısıyla bir istisna gibi gözükse de ilk 5 faktör (deneyime açıklık, nevrotiklik, dışadönüklük, uyumluluk ve bilinçlilik) BBM ile birebir aynıdır.

Yakın dönemdeki bazı çalışmalar kişilik özellikleri ile yaratıcılık arasında ilişkiyi sağlam bir temele oturtma çabası içindedir (Batey ve Furnham, 2006; Baas, Roskes, Sligte Nijstad ve De Dreu, 2013). Bu çalışmalardan, Batey ve Furnham'ın (2006) derlemesi farklı yaratıcılık tipleri (günlük, sanatsal ve bilimsel) ile kişilik özellikleri arasındaki ilişkiyi yorumlamak için önemli bir dayanak noktasıdır. Yazarlar, geçmiş çalışmaların sonuçlarına dayanarak, farklı kişilik özelliklerinin yaratıcılığın boyutları üzerinde farklı yönde ve düzeyde etkisi olabileceğini öne sürmüşlerdir. Batey ve Furnham (2006), kişilik faktörleri ile yaratıcılık boyutları arasındaki ilişkiye yönelik çıkarımları Tablo 1'de sunulmuştur. Meselâ, deneyime açıklığın her üç yaratıcılık alt tipiyle pozitif korelasyonu olduğunu, nevrotikliğin ise sanatsal yaratıcılık için olumlu bir özellik olduğunu fakat bilimsel veya günlük yaratıcılık için 
olumsuz bir kişilik özelliği olduğu belirtilmiştir. Tablodan da anlaş1lacağ1 gibi, yazarlar her kişilik özelliğinin, bütün yaratıcılık alt tipleri ile ilişkili olduğunu belirtmişlerdir. Ancak bu çalışmada da yaratıcılık alt tiplerinin ölçüm farklılıklarına ve bu farklılıkların, yaratıcılık-kişilik ilişkisini açıklayan çalışmalardaki etkilerine çok az değinilmiştir.

Tablo 1. Batey ve Furnham'ın (2006) Çalışmasına Göre Yaratıcılık ve Kişilik İlişkisi

\begin{tabular}{llll}
\cline { 2 - 4 } & \multicolumn{3}{c}{ Yaratıcılı Boyutu } \\
\hline Kişilik Özelliği & Sanatsal & Bilimsel & Günlük \\
\hline Nevrotiklik & Çok güçlü pozitif ilişki & Güçlü negatif ilişki & Zayıf negatif ilişki \\
Dışadönüklük & Güçlü negatif ilişki & Zayıf negatif ilişki & Güçlü pozitif ilişki \\
Deneyime Açıklık & Çok güçlü pozitif ilişki & Çok güçlü pozitif ilişki & Güçlü pozitif ilişki \\
Uyumluluk & Güçlü negatif ilişki & Zayıf negatif ilişki & Zayıf pozitif ilişki \\
Özdisiplin & Güçlü negatif ilişki & Çok güçlü pozitif ilişki & Zayıf pozitif ilişki
\end{tabular}

${ }^{1}$ Batey ve Furnham'dan (2006) uyarlanmıştır.

Baas ve diğer. (2013) ise yaratıcılığın bilişsel esneklik ve bilişsel sebat yoluyla ortaya çıktığını öne sürdükleri İki Yönlü Yaratıcılık Modeli'ne (IYYM) (Nijstad, De Dreu, Rietzschel ve Baas, 2010) dayanarak kişilik ve yaratıcılık ilişskisini açıklama yoluna gitmişlerdir. Yazarlara göre, dışadönüklük ve deneyime açıklık bilişsel esnekliği arttırarak yaratıcılığ 1 ortaya çıkarmaktadır. Nevrotiklik ise bilişsel sebatı arttırarak yaratıcı ürünlerin oluşmasını sağlamaktadır. Fakat yazarlar, bu görüşlere yönelik çok kısıtlı ampirik destek sunmuşlar ve kişilik özellikleri ile yaratıcılık arasındaki ilişkide esneklik ve sebatın aracılık rolünün daha fazla incelenmesi gerekliğine vurgu yapmışlardır.

Batey ve Furnham'ın (2006), yaratıcılıkla kişilik özellikleri arasındaki ilişkide ürünün türüne (akademik, günlük ve sanatsal) vurgu 
yaparken, Baas ve diğer. (2013), değişik kişilik özelliklerinin yaratıcılığa etkisindeki farklı aracı faktörlere (sebat ve esneklik) önem vermektedir. Bir başka yaklaşım ise Lonergan, Scott ve Mumford'un (2004) yaratıc1lığ 1 düşünce üretimi (idea generation) ve düşünce değerlendirme (idea evaluation) olarak iki adımda incelediği yaklaşımdır. Lonergan, Scott ve Mumford'un (2004) yaklaşımlarında kişilik faktörüne değinmemişlerdir; fakat çalışmalarında düşünce üretimi ve düşünce değerlendirme aşamalarında farklı bilişsel ve çevresel faktörlerin etkili olduğunu göstermişlerdir.

$\mathrm{Bu}$ çalışmada ise geçmiş araştırma sonuçları yaratıcılık ölçümünde kullanılan araçlar temel alınarak ele alınacaktır. Aynı zamanda bu araştırma sonuçları, Baas ve diğer. (2013)'nin IYYM ve Lonergan'ın iki adım modeli (two step model) yönünden tartışılacaktır. Batey ve Furnham'ın (2006) bulduğu farklılıklar sebebiyle, öncelikle günlük yaratıcılığı ölçen çalışmalar incelenecek olup; akademik ve sanatsal yaratıcılığı ilişkin sonuçlar ise Feist' in (1998) meta analiz çalışması ve Batey ve Furnham'ın (2006) derlemesi kapsamında değerlendirilecektir.

İlk olarak, Guilford'dan (1967) bu yana yaratıcılığın önemli bir bileşeni olarak değerlendirilen Iraksak Düşünme testleri değerlendirilecektir. Daha sonra ıraksak düşünme ölçümü, özbildirim raporları, yaratıcı başarı ölçümleri ve son olarak akademik ve sanatsal yaratıcılığa ilişkin meta analiz ve derleme çalışmalar incelenecektir.

\section{Günlük Yaratıcılık ve Iraksak Düşünme Testleri}

Iraksak düşünme, yaratıcılığın iki boyutundan biri olarak ele 
alınmaktadır (Guilford, 1967). Diğer boyut ise yakınsak düşünme olarak adlandırılır. Günümüzde yaratıcılık ölçümlerinin birçoğu raksak düşünme testlerini temel almaktadır ve rraksak düşünme test sonuçları yaratıcılık puanı olarak sunulmaktadır. Yakınsak düşünmenin önemine vurgu yapan bazı yazarlar, ıraksak düşünme ile yaratıcılığın bazı çalışmalarda eşanlamlı olarak kullanılmasına yönelik itirazlarını daha sık dile getirmektedirler (Cropley, 2006; Piffer, 2012).

Torrance Yaratıcı Düşünme Testi, Guilford Alternatif Kullanım, Doğurgular Testi (Consequences Tests) gibi testler rraksak düşünmeyi değerlendirmede en sık kullanılan ölçme araçlarıdır. Uzak Çağrışımlar Testi (RAT) ise yakınsak düşünmeyi ölçtüğü varsayılan ve en sık kullanılan ölçüm aracıdır.

\section{Torrance Yaratıcı Düşünme Testi}

Torrance (1990)'ın Torrance Yaratıcı Düşünme Testi (Torrance Tests of Creative Thinking; TTCT), sözel ve şekilsel yaratıcılık olmak üzere iki alt ölçekten oluşmaktadır (akt; Kim, 2006).

King, Walker ve Broyles (1996) TTCT'nin sözel yaratıcılık alt ölçeği ile Büyük Beşli Envanteri’ni (Big Five Inventory; BFI) (John, Donahue, ve Kentle, 1991; akt. King, Walker ve Broyles, 1996) kullandıkları çalışmalarında, sözel yaratıcılık ile dışadönüklük $(r=.26$, $p<.05)$ ve deneyime açıklık $(r=.38, p<.01)$ arasında anlamlı ilişki bulmuşlardır. Yazarlar aynı zamanda deneyime açıklığın, yaratıcı yetenekle, yaratıcı ürün üretme arasındaki ilişkide aracı rolü oynadığını göstermiştir. Sonuçlar yaratıcılıkla (TTCT sözel alt testi), ürün arasındaki pozitif korelasyonun, deneyime açıklığın yüksek olduğu du- 
rumlarda gözlemlendiğini göstermektedir.

\section{Guilford Alternatif Kullanım Testi}

Bir başka rraksak düşünme testi ise Guilford'un (1967) Guilford Alternatif Kullanım Testidir (GAKT) (akt; Furnham ve Bachtiar, 2008). Furnham ve Bachtiar (2008) çalışmalarında yaratıcılığı GAKT, özbildirim ve yaratıcı davranış biyografik envanteri (YDBE) kullanarak değerlendirmişlerdir. Kişiliği ise Costa ve McCrae'ın (1992) Büyük Beşli NEO-FFI (Big Five NEO-FFI) (akt; Furnham ve Bachtiar, 2008) ölçmüşlerdir. Bu çalışmada kişilik değişkenlerinden nevrotiklik ( $r=.36$, $p<.001)$, dişadönüklük $(r=.69, p<.001)$ ve uyumluluk $(r=.22, p<.001)$ ile ıraksak düşünme puanı arasında anlamlı pozitif ilişki bulunmuştur. Özbildirim yaratıcılık puanı ile sadece dışadönüklük $(\mathrm{r}=.17, p<.05)$ arasında düşük düzey bir ilişki saptanmıştır. Yaratıcılık ölçümlerinin kendi aralarındaki korelasyonlarına bakıldığında; GAKT puanı ile özbildirim arasında düşük fakat anlamlı pozitif korelasyon $(r=0.18$, $p<.05)$, GAKT ile YDBE arasında orta düzeyde anlamlı pozitif korelasyon $(r=.44, p<.01)$ ve özbildirim ile YDBE arasında ise düşük düzeyde anlamlı pozitif korelasyon $(r=.22, p<.01)$ bulunmuştur. Furnham, Batey, Anand ve Manfield da (2008) yaratıcılık ölçümünde GAKT ve YDBE testleri ile özbildirim değerlendirmesini kullanmışlardır. Kişilik ölçümü olarak ise NEO-FFI kullanılmıştır. Çalışma sonucunda rraksak düşünme ile dişadönüklük $(r=.26, p<.01)$ ve deneyime açıklık $(r=.22, p<.01)$ arasında pozitif yönde düşük düzeyde istatistiksel olarak anlamlı ilişki bulunmuştur. Özbildirim ve YDBE yaratıcılık puanları da sadece dışadönüklük ve deneyime açıklık ile ilişkili bulunmuştur. Yaratıcılık ölçümlerinin kendi aralarındaki kore- 
lasyonları ise .20 ile .33 arasında bulunmuştur.

Alternatif Kullanım Testi'nin (AKT) kullanıldığı bir başka çalışma ise Silvia, Nusbaum, Berg, Martin ve O’Connor (2009) tarafından yapılmıştır. Silvia ve arkadaşları AKT'ye ek olarak yaratıcılığa yönelik özbildirim ölçeklerini de kullanmışlardır. Bu çalışmada AKT cevapları hem akıcılık (verilen cevap sayısı) hem de kalite (hakemlerin cevapların kalitesine verdiği puan) yönünden analiz edilmiştir. Kişilik ölçümü ise Beş Faktör Envanteri (Five Factor Inventory; FFI.) (Costa ve McCrae, 1992, akt; Silvia ve ark., 2009) kullanılarak gerçekleştirilmiştir. Deneyime açıklık hem akııılık $(r=.246, p<.05)$ hem de kalite $(r=.268, p<.05)$ ile pozitif yönde ilişkili bulunmuştur. Batey, Chamarro-Premuzic ve Furnham'in (2009) GAKT ve NEO-PI-R kullanarak yaptıkları çalışmanın korelasyonel analizinde ise düşünce sayısıyla ilişkili tek kişilik faktörü dişadönüklük $(r=.23, p<.05)$ olarak bulunmuştur. Zekâ ve kişilik faktörlerini regresyon analizine dâhil ettiklerinde ise yaratıcılık üzerinde dışadönüklügün pozitif, uyumluluğun ise negatif etkisinin olduğu bulunmuştur. Batey, Furnham ve Safiullina'nın (2010) çalışmasında ise AKT ile kişilik özellikleri arasında herhangi bir ilişki bulunmamıştır.

\section{Doğurgular Testi (Consequences Tests)}

Doğurgular testinde denekler varsayımsal bir durum (örn., eğer bütün bebekler 2. başparmakla doğmaya başlasaydı ne olurdu? Veya insanlar âniden yemek yemeye ihtiyaç duymasalardı ne olurdu?) karŞ1sında neler olabileceğini listelerler (Christensen, Merrifield ve Guilford, 1958, akt; Furnham, Crump, Batey ve Chamarro-Premuzic, 
2009). Doğurgular testinde katılımcıların tepkileri, akıcılık (ifade edilen düşünce sayısı), kalite (düşüncelerin ne kadar anlamlı olduğu), orijinallik ve komplekslik (tepkinin birden çok element içermesi ve bu elementlerin etkileşimi) gibi farklı kategoriler üzerinden değerlendirilebilir.

Furnham ve arkadaşlarının (2009) çalışmasında, doğurgular testi orijinal düşünce sayısı ile nevrotiklik negatif, dışadönüklük ve deneyime açıklık ise pozitif ilişkili bulunmuştur. Fakat 5 Kişilik Faktörü, orijinal düşünce sayısındaki varyansın sadece \%10'unu açıklamaktadır. $\mathrm{Bu}$ testi kullanan bir başka çalışmada ise büyük beşliden sadece dışadönüklük ile ıraksak düşünme performansı arasında pozitif ilişki bulunmuştur (Furnham ve Nederstrom, 2010).

Doğurgular Testi'ni, Alternatif Kullanım Testi ile karşılaştıran bir çalışmada bu testin düşük uyum geçerliğine ve güvenirliğe sâhip olduğu öne sürülmektedir (Silvia, 2011). Bu durum doğurgular testine ilişkin verilere daha ihtiyatlı yaklaşmamızı gerektirse de dışadönüklük ve deneyime açıklığa ilişkin değerlendirmeler genellikle literatürle uyumludur.

\section{Uzak Çağrışımlar Testi (Remote Associates Test; RAT)}

RAT 1962 y1lında Mednick tarafından geliştirilmiştir. Mednick (1962), çağrışımsal belleğe atıfta bulunarak, uyaranların yaratıcı insanlarda diğer insanlara göre farklı çağrışımlar yaptığını öne sürmüştür. Makalesinde "masa" örneğini kullanan Mednick, masa dendiğinde birçok insanın aklına sandalye geldiğini, sandalyenin masa uyaranı için klişe tepki olduğunu öne sürmüştür. Mednick yaratıcı bireylerin uya- 
ranlar karşısındaki tepkilerinin daha az klişe cevaplar içerdiğini belirtmiştir.

Mednick bu yaklaşımından yola çıkarak katılımcılara üç kelimenin verildiği ve katılımcılardan bu üç kelimeyle ilişkili dördüncü kelimeyi bulmaları istenen RAT'i geliştirmiştir. Örnek bir RAT maddesi olarak; "kayan" (falling), "aktör" (actor) ve "toz" (dust) kelimelerinin verilip, doğru cevabın "yıldız" (star) olduğu zorluk derecesi en düşük olan madde verilebilinir. Mednick, zorluk derecesi arttıkça yaratıcı insanların, diğerlerine göre daha başarılı olacağını çünkü çağrışımsal belleklerindeki uyarılmanın daha geniş bir yelpazede olacağını iddia etmiştir.

RAT puanı ve kişilik özellikleri arasındaki ilişkiyi inceleyen çalışmalardan biri Richardson (1985) tarafindan yapılmıştır. Richardson, kişilik özellikleri olarak, belirsizliğe tolerans, özdisiplin, baskınlık gibi değişkenlerle birlikte dişadönüklüğü de incelemiştir. Çalışma sonucunda RAT puanı ile dışadönükük arasında düşük düzeyde pozitif ilişki $(r=.203, p=.01)$ bulmuştur. Bu çalışmanın bir başka önemli bulgusu ise, yaratıcılıkla ilgili 40 sıfatı kullanarak, özbildirimle ölçülen yaratıc1lık ile RAT puanı arasında herhangi bir ilişki $(r=.133, p>.05)$ bulunmamasıdır. Fakat özbildirimle ölçülen yaratıcılıkla dışadönüklük arasında kuvvetli pozitif ilişki $(r=.505, p=.01)$ bulunmuştur.

Martindale ve Daley'in (1996) yaratıcılığı ölçmek için Palermo ve Jenkins'in (1964) (akt; Martindale ve Daley, 1996) kelime çağrışım testini kullandıkları çalışmada, kişilik ölçümü için ise Eysenck Kişilik Envanteri (Eysenck ve Eysenck, 1975, akt; Martindale ve Daley, 1996) 
ve NEO Kişilik Envanteri'ni (Costa ve McCrae, 1985, akt; Martindale ve Daley, 1996) kullanmışlardır. Çalışma sonucunda çağrışım puanları ile sadece Eysenck Kişilik Envanteri'nin dışadönüklük boyutu arasında orta düzey bir ilişki $(r=.33, p<.05)$ bulunmuştur. Fakat Eysenck nörotisizm, NEO-deneyime açıklık, NEO-dışadönüklük, NEO-uyumluluk ve NEO-özdisiplin ölçekleri ile çağrışım puanları arasında herhangi bir anlamlı ilişki bulunmamıştır. Yazarlar aynı zamanda Alternatif Kullanım Testini de (Alternative Uses Test) (Christensen, Guilford, Merrifield ve Wilson, 1960, akt; Martindale ve Daley, 1996) katılımcilara uygulamışlardır. Sonuçlar, Alternatif Kullanım Testi ile Eysenck d1şadönüklük $(r=.33, p<.05)$, NEO-dişadönüklük $(r=.32, p<.01)$ arasında anlamlı pozitif ilişkiye, NEO-nörotisizm $(r=-.34, p<.05)$ ile negatif ilişkiye işaret etmektedir. Özetle RAT puanı ile kişilik özelliklerden dışadönüklük ve deneyime açıklık birçok çalışmada tutarlı olarak ilişkili bulunmuştur.

\section{Özbildirim Ölçekleri ve Yaratıcı Başarı Ölçeği}

Özbildirim ölçeklerini iki gruba ayrılmaktadır. İlk grup yaratıcı davranışların ya da yaratıcı başarıları ölçüldüğü YDBE ve YBÖ gibi ölçeklerin kullanıldığı çalışmalardır. İkinci grup ise bireylerin kendilerini ne kadar yaratıcı olarak değerlendirdiklerini puanladıkları ölçek çalışmalarıdır. Yaratıcılık çalışmalarında özbildirim ölçekleri genellikle önceki bölümlerde bahsettiğimiz farklı ölçüm araçlarıyla birlikte kullanılır. Fakat alanyazında YDBE ya da Yaratıcı Başarı Ölçeği (YBÖ) gibi özbildirim ölçeklerinin tek olarak kullanıldığı çalışmalara rastlamakta olasıdır. YBÖ’nün diğer ölçüm araçlarına kıyasla en önemli avantajı, bireylerin ortaya çıkardığı yaratıcı ürünleri değerlen- 
dirme firsat1 vermesidir.

Bu tarz çalışmalardan biri Hirsh ve Peterson (2008) tarafından yapılmıştır. Yazarlar bu çalışmada, yaratıcılık ölçümü için yaratıcı başarı ölçeğini kullanmışlardır (Creative Achievement Questionnaire; CAQ) (Carson, Peterson ve Higgins, 2005, akt; Hirsh ve Peterson, 2008). Kişilik ölçümü için ise Büyük Beşli Envanteri'ni (Big Five Inventory) (John, Donahue ve Kentle, 1991, akt; Hirsh ve Peterson, 2008) kullanmışlardır. Alanyazındaki benzer çalışma sonuçlarına paralel şekilde (Batey, Furnham ve Safiullina, 2010), deneyime açıklık ile YBÖ arasında anlamlı pozitif ilişki bulunmuştur.

Deneyime açıklık, Yaratıcı Davranış Envanteri (Creative Behavior Inventory; CBI) (Dollinger, 2007, akt; Silvia ve diğer., 2009) ile ölçülen yaratıcılıkla da ilişkili $(r=.624, p<.05)$ bulunmuştur.

Yaratıcılığın özbildirimle ölçüldüğü çalışmalarda ise, genellikle yaratıcılıkla deneyime açıklık arasında pozitif bir ilişki saptanmaktadır (Furnham ve Bachtiar 2008; Furnham, Batey, Anand ve Manfield 2008; Batey, Furnham ve Safiullina, 2010). Bazı çalışmalar dışadönüklüğe ek olarak deneyime açıklık ile özbildirim değerlendirmesi arasındaki ilişkiye de işaret etmektedir (Furnham, Batey, Anand ve Manfield, 2008; Richardson, 1985).

\section{Sanatsal, Bilimsel Yaratıcılık ve Kişilik}

Feist (1998) meta-analiz çalışmasında sanatçıların ve sanatçı olmayanların kişilik özelliklerini karşılaştırmıştır. Feist (1998) kişilik ölçümlerini beş faktör modeli, Eysenck kişilik envanteri, 16 kişilik faktörü envanteri ve Kaliforniya Psikolojik Envanteri'ne dayandıran 
çalışmaları analizine dâhil etmiştir. Çalışma sonucunda beş faktör yapısından özdisiplinin sanatsal yaratıcılıkla negatif ilişkili olduğunu, deneyime açıklığın ise pozitif ilişkili olduğunu öne sürmüştür. Diğer kişilik ölçümlerinden esneklik, imgeleme, hassasiyet, radikallik, psikotizm özyeterliğin pozitif; sosyalleşme, sorumluluk, iyi oluş, tolerans ve uyumun ise negatif ilişkili olduğu bulunmuştur. Batey ve Furnham (2006) geniş kapsamlı derlemelerinde sanatsal yaratıcılığın psikotizm, deneyime açıklık ve nevrotiklikle pozitif, özdisiplin ve dışadönüklükle negatif ilişkili olduğunu öne sürmüşlerdir.

Feist (1998) kişilik ve akademik yaratıcılık ilişkisini incelerken geçmiş çalışmaları iki grupta değerlendirmiştir. İlk olarak bilim insanı olanların ve olmayanların kişilik özelliklerini inceleyen çalışmaları değerlendirmiştir. Daha sonra, yaratıcılığı yüksek ve düşük olan bilim insanlarının kişilik özelliklerini araştıran çalışmaları incelemiştir. Kişilik sonuçları ise sanatsal yaratıcılıktaki aynı ölçekler üzerinden yorumlamıştır. Çalışma sonucunda bilim insanlarının, bilim insanı olmayanlara göre daha özdisiplinli; fakat daha az dışadönük ve deneyime açık olduğu bulunmuştur.

Yaratıcı olan ve olmayan bilim insanlarının kişilik özellikleri incelendiğinde ise, daha yaratıcı olan bilim insanlarının aynı zamanda daha dışadönük, deneyime açık ve özdisiplinli olduğu ortaya çıkmıştır. Batey ve Furnham'a (2006) göre ise akademik yaratıcılık deneyime açıklık ve özdisiplinle yüksek derecede pozitif ilişkili fakat nevrotiklik ve dışadönüklük ile düşük derecede negatif ilişkilidir. 


\section{Yaratıcılık Ölçeklerinin Kendi Aralarındaki Güvenirliği}

Batey ve Furnham (2008) farklı yaratıcılık ölçümlerinin (Guilford AKT akıcılık, Hakem Değerlendirmesine Dayalı Yaratıcılık; HDDY, Yaratıcı Davranış Biyografik Envanteri ve Özbildirim) korelasyonlarını da incelemişlerdir. Yazarlar ayrıca, bu dört ölçümün Z skorlarının toplamını alarak toplam yaratıcılık puanı da hesaplamışlardır. AKT ile HDDY arasında yüksek anlamlı ( $r=.79)$, YDBE ile düşük anlamlı ( $r=.21)$, özbildirim ile anlamsız ilişki bulmuşlardır. HDDY ile YDBE arasında anlamsız, özbildirim ile düşük anlamlı ilişki $(r=.22)$ bulunmuştur. Son olarak YDBE ile özbildirim arasında orta derecede anlamlı ilişki ( $r=.33)$ bulunmuştur. Toplam yaratıcılık puanı, bütün diğer yaratıcılık ölçümleri ile yüksek seviyede ilişkili bulunmuştur. $\mathrm{Bu}$ ilişki ise toplam yaratıcılık hesaplamasının doğasından kaynaklanmaktadır.

Furnham ve Bachtiar (2008) çalışmalarında; GAKT puanı ile özbildirim arasında düşük fakat anlamlı pozitif ilişki $(r=0.18, p<.05)$, GAKT ile YDBE arasında orta düzeyde anlamlı pozitif ilişki $(r=.44$, $p<.01)$ ve özbildirim ile YDBE arasında ise zayıf pozitif ilişki $(r=.22$, $p<.01)$ bulmuştur.

\section{Tartışma}

$\mathrm{Bu}$ çalışmanın en önemli sınırlılığı yaratıcılık, kişilik ilişkisini beş faktör modeli dışında ele alan yayınları kapsamamasıdır. Bu çalışmalardan en kapsamlısı Feist ve Barron'un (2003) 45 yıl süren boylamsal çalışmasıdır. Yaratıcılık ve kişilik ilişkisini inceleyen bütün çalışmaların ele alınmaması ise bir başka önemli sınırlılık olarak gös- 
terilebilir. Bu sınırlılıklara karşın ele alınan çalışmaların yaratıcılık, kişilik ilişkisinde şimdiye kadar bulunan çalışmaları yansıttığı düşünülmektedir.

Bu sınırlılıklara ek olarak bu yazının değerlendirilmesi yapılırken Mischel'in (1973) kişilik özellikleri ve davranış arasında çok düşük ilişki olduğuna dâir tezlerini de göz önüne almak gerekir. Mischel'e göre (1973) davranış ve performansın sergilenmesi kişilik özelliklerinden çok ortamsal değişkenlerle ilişkilidir. Mischel aynı zamanda ortamsal değişkenlerin kişilik özelliklerinin dışavurumunu etkilediğgini ve istikrarlı olduğu varsayılan kişiliğin gerçekte değişken olduğunu (çevre ile etkileşim sonucunda) savunmaktadır. Mischel'in yaklaşımı gözönüne alındığında yaratıcılığın ortaya çıkma sürecinde kişilik özellikleriyle etkileşime girebilecek çevresel faktörlerin analizi de büyük önem taşımaktadır. Ödüllendirme, cezalandırma, duygudurum gibi çevresel faktörlerle sosyal beğenirlik ve kendini sansürleme gibi grup çalışmalarında ortaya çıkabilecek bireysel değişkenlerin kişilikle etkileşimlerinin çalışılması konunun aydınlatılması yönünden önem taş1maktadır.

Sonuçlar genel olarak değerlendirildiğinde, dişadönüklük ve deneyime açıklık farklı düzeylerde olsa da yaratıcılığı arttıran önemli kişilik özellikleri olarak göze çarpmaktadır. Nevrotiklik ve özdisiplin ile yaratıcılık arasındaki ilişkiler ise yaratıcılığın türüne göre değişiklik göstermektedir. Nevrotiklik sanatsal yaratıcılıkta olumlu bir özellik olarak ortaya çıksa da akademik yaratıcılıkta olumsuz, günlük yaratıc1lıkta ise etkisiz bir kişilik özelliği olduğu değerlendirilmektedir. Öz- 
disiplin ise sanatsal ve günlük yaratıcılıkta etkisiz bir özellikken, akademik yaratıcılıkla yüksek pozitif ilişkili bir değişkendir.

Kişilik ve yaratıcılık ilişkisi ölçüm araçları açısından değerlendirildiğinde ilk dikkati çeken nokta özbildirim ölçekleriyle ölçülen yaratıcılık ile dışadönüklük ve deneyime açıklık arasında gözlemlenen yüksek korelasyonlardır. Bu korelasyon değerleri diğer ölçüm araçlarıyla kıyaslandığında daha yüksek bir ilişkiye işaret etmektedir. $\mathrm{Bu}$ ilişkinin bir kaynağının sosyal beğenirlik olduğu değerlendirilebilir. Sosyal beğenirlik katılımcıların olumlu veya ideal özellikleri kendilerine olumsuz özelliklerden daha fazla atfetmesidir. Bu nedenle özbildirim ölçekleri kullanılarak gerçekleştirilen çalışmalarda katılımcılar yaratıcılık, deneyime açıklık ve dışadönüklük gibi olumlu bileşenlere âit maddeleri kendilerine daha uygun görme eğiliminde olabilirler. Sonuçta bu araştırmalarda olumlu kişilik özellikleri ile yaratıcılık arasında daha kuvvetli bir ilişkinin bulunması daha olasıdır.

Ölçüm araçlarının kendi arasındaki düşük korelasyonun birden fazla nedeni olabilir. İlk neden ölçüm araçlarının tek bir yapıyı (yaratıcılık) değil birden fazla yapıyı ölçmesinden kaynaklanabilir. İkinci neden ise yaratıcılığın ya da yaratıcılık boyutlarının (sanatsal, akademik, günlük) farklı zihinsel süreçleri (rraksak/yakınsak düşünme veya sebat/esneklik) içermesidir. Bu durumda kullanılan ölçüm araçlarını yaratıcılığı değil, yaratıcılığın boyutlarından birinde (örneğin günlük) kullanılan tek bir bilişsel süreci (rraksak düşünme) ölçen araçlar olarak adlandırmak daha doğru olacaktır.

Alanyazın IYYYM açısından incelendiğinde, özellikle doğurgular 
testi kullanılarak yapılan çalışmalarda dişa dönüklükle, deneyime açıklığın üretilen düşünce sayısı ve esneklikle ilişkili bulunması bu modeli destekler niteliktedir. Fakat, modelin doğrulanması için nevrotik kişilik özelliği ile sebat arasında beklenen ilişkiyi gösteren çalışmalar mevcut değildir.

İki adım modeline göre yaratıcılık, düşünce üretimi ve seçiminden oluşan iki adımda gerçekleşir. Günümüzde sıklıkla kullanılan 1raksak düşünme testleri veya envanterleri yaratıcılığın düşünce üretimi adımını ölçmektedir. Düşünce seçimi ise yaratıcılığın yakınsak düşünmeyi gerektiren bölümüdür. Bu iki adımda farklı kişilik özelliklerinin etkin olacağını düşünmek gerçekçi bir beklentidir. Bir üniversitenin nasıl geliştirileceği konusunda herkesin fikri olabilir; fakat büyük ihtimalle daha dışadönük ve yeni deneyimlere açık kişilerin diğerlerine nazaran daha çok düşüncesi olacaktır. Fakat hangi düşüncelerin uygulanabilir, kullanışı, gerçekçi olduğu konusunda deneyimli, bilgi birikimi olan ve bu konuda çalışan kişilerin kararlarının daha isabetli olması beklenir. Karar alırken, konu üzerinde daha uzun süredir ve daha detaylı düşünen, plân yapan kişiler, bir diğer deyişle özdisiplini yüksek kişiler daha makul kararlar alacaklardır.

Alanyazında günlük yaratıcılığı ölçen testlerin birçoğunun üretilen düşünce sayısı veya düşünce sayısı ile yüksek korelasyonu bulunan esneklik, orjinallik, uygulanabilirlik gibi faktörleri değerlendirdiği düşünüldüğünde, bu testlerle kişilik boyutlarından dışadönüklük veya deneyime açıklığın ilişkili çıkması beklenen bir sonuçtur. Sadece düşünce üretimini değil, düşünce seçimi ve uygulamayı da kapsayan 
bilimsel yaratıcılığın ise özdisiplinle ilişkili çıkması, bilimsel yaratıcılıkta ikinci adımın daha ağır bastığının göstergesidir.

$\mathrm{Bu}$ yaklaşımı destekleyebilecek bir başka sonuç ise, bireylerin veya grupların karar verme süreçlerindeki başarısızlıklarını gösteren çalışmalardır (Rietzschel, Nijstad ve Stroebe, 2006). Düşünce üretiminde iyi performans gösteren birey/gruplar, uygulanabilir, gerçekçi ya da kaliteli düşünceleri seçmekte başarısız olmaktadırlar. Bu çalışmalardaki başarısızlık ölçüsünün, katılımcıların, uzmanların seçtiği fikirleri seçmemesi olduğunu unutmamak gerekir. Kısacası, ilk adımda (düşünce üretimi) başarılı olan bireyler ya da gruplar, ikinci adımda (düşünce seçimi) işin uzmanlarının performansına ulaşamamaktadır. $\mathrm{Bu}$ sonuç, yaratıcılığın ya da yaratıcı ürünün ortaya çıkması için, tecrübe ve bilgi birikiminin en az rraksak düşünme kadar gerekli olduğunu göstermektedir.

Bu bilgiler 1şığında yaratıcılıkla kişilik özellikleri arasındaki incelemeyi amaçlayan çalışmaların iki adım modelini temel alarak gerçekleştirilmesi gerekmektedir. Bu tarz çalışmalar düşünce üretimi ve düşünce seçimi ile ilişkili kişilik özelliklerinin ayırt edilmesini sağlayabilir. Bu çerçevede sanatsal, bilimsel ya da günlük yaratıcılıkta düşünce üretimi açısından deneyime açıklık ve dışadönüklüğün önemi ortaya çıkarılabilir. Ayrıca düşünce seçiminde ya da ürünün ortaya çıkarılmasında yaratıcılığın farklı boyutları için etkili olabilecek farklı kişilik özelliklerinin belirlenmesi mümkün olabilir.

Gelecek çalışmaların, yaratıcılığın farklı boyutlarını ele alırken, her boyut için gerekli olan düşünsel süreçleri ve bu süreçlerin nasıl 
ölçüleceğine dâir güvenilir yöntemleri tespit etmesi gerekecektir. Kişilik faktörlerinin, zekânın, çevresel uyaranların veya duygu durumun değişik zihinsel süreçler üzerinde farklı etkileri olabileceğini göz önüne alan araştırma desenleri yaratıcılığı etkileyen faktörleri daha sağlıklı bir şekilde anlamamızı sağlayacaktır.

\section{Kaynakça}

Almeida, L. S., Prieto, L.P., Ferrando, M., Oliveira, E. ve Ferrandiz, C. (2008). Torrance test of creative thinking: The question of its construct validity. Thinking Skills and Creativity, 3, 53-58. doi:10.1016/j.tsc.2008.03.003

Ayas, M.B. ve Sak, U. (2014). Objective measure of scientific creativity: Psychometric validity of the Creative Scientific Ability Test. Thinking Skills and Creativity, 13, 195-205.

doi:10.1016/j.tsc.2014.06.001

Baas, M., Roskes, M., Sligte, D., Nijstad, B. A. ve De Dreu, C. K. W. (2013). Personality and creativity: The dual pathway to creativity model and a research agenda. Social and Personality Psychology Compass, 7, 732-748.

doi:10.1111/spc3.12062

Batey, M. ve Furnham, A. (2006). Creativity, intelligence, and personality: a critical review of the scattered literature. Genetic, Social, and General Psychology Monographs, 132(4), 355-429.

Batey, M. ve Furnham, A. (2008). The relationship between measures of creativity and schizotypy. Personality and Individual Differences, 816-821.

doi:10.1016/j.paid.2008.08.014 
Batey, M., Chamorro-Premuzic, T. ve Furnham, A. (2009). Intelligence and personality as predictors of divergent thinking: The role of general, fluid and crystallised intelligence. Thinking Skills and Creativity, 4, 60-69.

doi:10.1016/j.tsc.2009.01.002

Batey, M., Furnham, A. ve Safiullina, X. (2010). Intelligence, general knowledge and personality predictors of creativity. Learning and Individual Differences, 20, 532-535.

doi:10.1016/j.lindif.2010.04.008

Cropley, A. (2006). In praise of convergent thinking. Creativity Research Journal, 18, 391-404.

doi:10.1207/s15326934crj1803_13

Csikszentmihalyi, M. (2013). Creativity: The Psychology of Discovery and Invention. New York, NY: Harper Perennial Classics.

Feist, G. J. (1998). A meta-analysis of the impact of personality on scientific and artistic creativity. Personality and Social Psychological Review, 2, 290-309.

Feist, G. J. ve Barron, F. X. (2003). Predicting creativity from early to late adulthood: Intellect, potential, and personality. Journal of Research in Personality, 37, 62-88.

doi:10.1016/S0092-6566(02)00536-6

Folley, B. S. ve Park, S. (2005). Verbal creativity and schizotypal personality in relation to prefrontal hemispheric laterality: A behavioral and near-infrared optical imaging study. Schizophrenia Research, 80(2-3), 271-282.

Frederiksen, N. ve Ward, W. C. (1978). Measures for the study of creativity in scientific problem solving. Applied Psychological Measurement, 2(1), 1-24. 
Furnham, A., Batey, M., Anand, K. ve Manfield, J. (2008). Personality, hypomania, intelligence and creativity. Personality and Individual Differences, 44, 1060-1069. doi:10.1016/j.paid.2007.10.035

Furnham, A. ve Bachtiar, V. (2008). Personality and intelligence as predictors of creativity. Personality and Individual Differences, 45, 613-617. doi:10.1016/j.paid.2008.06.023

Furnham, A., Crump, J., Batey, M. ve Chamorro-Premuzic, T. (2009). Personality and ability predictors of the "Consequences" Test of divergent thinking in a large non-student sample. Personality and Individual Differences, 46, 536-540.

doi:10.1016/j.paid.2008.12.007

Furnham, A. ve Nederstrom, N. (2010). Ability, demographic and personality predictors of creativity. Personality and Individual Differences, 48, 957-961. doi:10.1016/j.paid.2010.02.030

Gençöz, T. ve Öncül, Ö. (2012). Examination of Personality Characteristics in a Turkish Sample: Development of Basic Personality Traits Inventory. The Journal of General Psychology, 139, 194-216.

doi: $10.1080 / 00221309.2012 .686932$

Goldberg, L. R., Johnson, J. A., Eber, H. W., Hogan, R., Ashton, M. C., Cloninger, C. R. ve Gough, G. H., (2006). The International Personality Item Pool and the future of public-domain personality measures. Journal of Research in Personality, 40, 84-96.

Guilford, J.P. (1967). Creativity: Yesterday, today and tomorrow. The Journal of Creative Behavior, 1, 3-14. 
Gültepe, B. (2014). Duygudurum ve bilişsel değişkenlerin beyin firtınasında yaratıcılı̆̆a etkisi. Yayımlanmamış yüksek lisans tezi, Abant İzzet Baysal Üniversitesi Sosyal Bilimler Enstitüsü.

Hirsh, J. B. ve Peterson, J. B. (2008). Predicting creativity and academic success with a "Fake-Proof" measure of the Big Five. Journal of Research in Personality, 42, 1323-1333. doi:10.1016/j.jrp.2008.04.006

Hoover, D. (1979). Measurement of Creativity: Review and Critique. 15 Haziran 2015, http://files.eric.ed.gov/fulltext/ED175916.pdf.

Hu, W. ve Adey, P. (2002). A scientific creativity test for secondary school students. International Journal of Science Education, 24(4), 389-403.

Jauk, E., Benedek, M., Dunst, B. ve Neubauer, A. C. (2013). The relationship between intelligence and creativity: New support for the threshold hypothesis by means of empirical breakpoint detection. Intelligence, 41, 212-221.

doi: 10.1016/j.intell.2013.03.003

Kim, K. H. (2006). Can we trust creativity tests? A review of the torrance tests of creative thinking (TTCT). Creativity Research Journal, 18, 3-14.

King, L. A., Walker, L. C. ve Broyles, S. J. (1996). Creativity and Five-Factor Model. Journal of Research in Personality, 30, 189-203.

Kyaga, S., Landén, M., Boman, M., Hultman, C. M., Långström, N. ve Lichtenstein, P. (2013). Mental illness, suicide and creativity: 40-year prospective total population study. Journal of Psychiatric Research, 47(1), 83-90. 
http://www.ncbi.nlm.nih.gov/pubmed/23063328

Lonergan, D. C., Scott, G. M. ve Mumford, M. D. (2004). Evaluative aspect of creative thought: effects of appraisal and revision standards. Creativity Reearch Journal, 16, 231-246.

doi:10.1080/1040419.2004.9651455

Martindale, C. ve Dailey, A. (1996). Creativity, primary process cognition and personality. Personality and Individual Differences, 20, 409-414.

Mayer, R. E. (1999). Fifty Years of Creativity Research, in Handbook of Creativity. New York, NY: Macmillan.

McCrae, R. ve Costa, P. T. (2004). A contemplated revision of the NEO Five-Factor Inventory. Personality and Individual Differences, 36, 587-596. doi:10.1016/S0191-8869(03)00118-1

Mischel, W. (1973). Toward a cognitive social learning reconceptualization of personality. Psychological Review, 80, 252-283.

Mednick, S. A. (1962). The associative basis of the creative process. Psychological Review, 69, 220-232.

Nijstad, B. A., De Dreu, C. K. W., Rietzschel, E. F. ve Baas, M. (2010): The dual pathway to creativity model: Creative ideation as a function of flexibility and persistence. European Review of Social Psychology, 21(1), 34-77. doi:10.1080/10463281003765323

Paulus, P. B. (2000). Groups, teams and creativity: The creative potential of idea generating groups. Applied Psychology: An International Review, 49, 237-262. 
Paulus, P. ve Nijstad, B. (2003). Group creativity: An introduction. P. Paulus ve B. Nijstad (Eds.), Group creativity: Innovation through collaboration içinde (3-11). New York: Oxford University Press.

Piffer, D. (2012). Can creativity be measured? An attempt to clarify the notion of creativity and general direction for future research. Thinking Skills and Creativity, 7, 258-264. doi:10.1016/j.tsc.2012.04.009

Richardson, A. G. (1985). Personality correlates of creativity among a sample Jamaican adolescents. Personality and Individual Differences, $6,771-774$.

Rietzschel, E. F., Nijstad, B. A. ve Stroebe, W. (2006). Productivity is not enough: A comparison of interactive and nominal brainstorming groups on idea generation and selection. Journal of Experimental Social Psychology, 42, 244-251.

doi:10.1016/j.jesp.2005.04.005

Silvia, P. J., Nusbaum, E. C., Berg, C., Martin, C. ve O'Connor, A. (2009). Openness to experience, plasticity, and creativity: Exploring lower-order, high-order, and interactive effects. Journal of Research in Personality, 43, 1087-1090.

doi:10.1016/j.jrp.2009.04.015

Silvia, P. J. (2011). Subjective scoring of divergent thinking: Examining the reliability of unusual uses, instances, consequences tasks. Thinking Skills and Creativity, 6, 24-30.

doi:10.106/j.tsc.2010.06.001

Torrance, E. P. (1965). Scientific views of creativity and factors affecting its growth. Creativity and Learning, 94, 663-681. 15 Mayıs 2015, http://www.jstor.org/stable/20026936. 
Walker, B. R. ve Jackson, C. J. (2014). How the five factor model and revised reinforcement sensitivity theory predict divergent thinking. Personality and Individual Differences, 57, 54-58. doi:10.1016/j.paid.2013.09.011

Yi, X., Plucker, J. A. ve Guo, J. (2015). Modeling influences on divergent thinking and artistic creativity. Thinking Skills and Creativity, 16, 62-68.

doi:10.1016/j.tsc.2015.02.002 